\title{
Choice and Evaluation of Hospitals in Bangladesh: Insights from Patients and Policy Implications
}

\author{
Syed Saad Andaleeb, Ph D
}

\begin{abstract}
Various aspects of bealth care services in Bangladesh, especially in the public sector, are not welldocumented. Based on a survey, this paper attempts to gain insights into the bealth care area from the perspectives of hospital patients. These insights provide a perspective that is different from that of bealth care providers; they also bave implications for bealth policy.
\end{abstract}

Key words: Bangladesh; hospital cboice; perceptions of patients; bealth policy

\section{Introduction}

The health care system and its ability to deliver sound health to its constituencies can have far-reaching implications for the economic, social, and political health of a nation. In Bangladesh, where the demand for health care services will continue to increase due to population and related pressures, the government sector has not successfully risen to the challenge of providing better access to health care. The World Bank in 1987 estimated that only 30 percent of the population had access to primary health care services. For those having access, the quality of services has been inadequate in terms of both basic and specialized needs. Accordingly, The World Bank rated the quality of public health care services unacceptably low by conventional standards.

As the public health care sector continues to perform inadequately, a variety of private health care facilities have taken root in the country. According to one estimate (Khan 1996), a total of 346 private hospitals and clinics were registered by 1996 with the Directorate of Hospitals and Clinics; more than half of them were registered in Dhaka city alone.

Syed Saad Andaleeb, Associate Professor of Marketing, School of Business, The Pennsylvania State University at Erie, Station Road, Erie; PA 165631403 USA - E-mail : ssa@psu.edu
With both private and public health care delivery systems existing side by side in the country, it is important to understand the dynamics of who uses these different systems, what influences their choices, how health care facilities are used, and how patients evaluate the services. Insights into these questions would suggest measures to strengthen the health care delivery system and to make it more responsive to the needs of the population it serves.

In addition, it can also shed light on the efficacy versus equity debate. A chief argument for the provision of public health care is that it leads to a more equitable distribution of benefits. Making health care widely available ensures a basic human right to a larger group, but supporting such a program can be costly. When public resources are severely limited, undesirable consequences can result, such as poor service, inadequate or incomplete care and, often, the evolution of a system of underhand payments that can be beyond the means of the general public.

Supporters of private health care believe that it will help improve quality and efficiency. While there is some evidence regarding the private sector's superiority in providing costeffective social services, there is also evidence that this sector may reduce quality by reducing inputs, disregard social 
pricing considerations, or, worse, try to increase their profits by providing services that may be unnecessary or even harmful (Van der Gaag 1995).

Whatever the arguments for or against public and private hospitals, a time-honored test of hospital efficacy lies in the views and preference patterns of those who select, use, and evaluate them. This study addresses patient or user behaviors regarding hospitals and clinics in public and private sectors in Bangladesh to suggest policy measures for improving health care delivery in Bangladesh. The following research questions were addressed: What factors influence choice of hospitals? Are the main reasons for hospital visits preventive or restorative? Is there an association between the type of hospital selected and demographic variables such as gender, education, and income? How do length of stay and patient satisfaction differ between types of hospital and demographic groups?

\section{Methodology}

Secondary research was conducted to identify studies on hospital selection and usage behavior in Bangladesh. Unfortunately, the research conducted on hospitals and health care in the country provided little guidance. In particular, the perspectives of hospital users or "customers" seem to have been largely ignored by the research community. Consequently, this study is grounded in survey data obtained from recipients of health care services in the country designed to address the research questions.

A preliminary version of the questionnaire was developed in English on the basis of insights from in-depth qualitative interviews with experts and users of hospitals. The instrument was translated next into the local language (Bangla) and then re-translated (to address the emic-etic dilemma) until a panel fluent in English and Bangla agreed that the two versions were reasonably comparable. A variety of measurement scales (nominal, interval, and ratio) were included in a structured format to examine the relationships between selected variables. Very few questions were openended because analysis and interpretation of such questions can be complex and subjective. The questionnaire was pretested several times to ensure that the wording, format, length, sequencing of questions, and range of selected scaleitems (5-point vs. 7-point) were appropriate. At each successive pre-test, feedback was obtained from approximately ten hospital users to help refine the survey instrument until it was ready for final data collection.

Because of resource and time constraints and the preliminary nature of this investigation, only 300 interviews were planned from Dhaka city. To obtain a probability sample, considerable effort was devoted to selecting the appropriate sampling plan. The population was defined as residents of Dhaka city who had utilized hospital services in the past twelve months.

In the absence of any lists from which a random sample of hospital users could be drawn, stage-wise area sampling was combined with systematic sampling so that every hospital user in Dhaka city had an equal chance of being selected. First, seventeen residential areas were randomly selected from a generated list of major residential areas in the city. The selected areas included Motijheel, Purana Paltan, Kamlapur, Lalbagh, Gopibagh, Imamganj, Dhanmandi, Mohammadpur, Lalmatia, Mirpur, Gulshan, Banani, DOHS, Uttora, Mohakhali, Rampura, and Malibagh. There was a general consensus that these areas adequately represented different socioeconomic groups in the city.

From each area, streets were randomly selected. Residential homes were chosen next using systematic sampling. Interviewers were given a letter of introduction from a wellrecognized private university so that residents would see that the study was authentic. A telephone number was also provided, in case respondents wanted to verify the identity of the investigators or clarify questions of concern.

Several difficulties were encountered during data collection. Not all the selected households included someone who was hospitalized in the past twelve months. Others refused to grant interviews because, being unfamiliar with such studies, they were suspicious of the interviewers or the purpose of the study.

Due to time and resource constraints, interviewers who were not able to complete the required number of surveys were given a second option of obtaining a probability sample. They were asked to go to population centers in the 17 selected areas, including bus and train stations, retail stores, 
banks, offices of private companies, and government establishments. With permission from these establishments, respondents were again selected using systematic sampling. Those who agreed to complete the survey were informed of the purpose of the study and assured anonymity. After a quick screening question on whether respondents used a hospital in the past twelve months, interviewers proceeded with the survey questions.

A total of 216 surveys were completed. Of these, nine were considered problematic due to excessive missing data, 'don't know' answers, N/A (not applicable) answers, and response biases. The data from these questionnaires were not included in the data set. Thus, a total of 207 surveys were analyzed; respondents indicated visiting 57 hospitals and clinics in Dhaka city.

\section{Analysis}

Frequency distributions were obtained to check for data entry errors (e.g., unrecognized or missing codes) and to obtain descriptive statistics. Mean and standard deviation were also obtained from the frequency analyses. To determine whether a significant association existed between nominal variables (e.g., income and type of hospital used), cross tabulation analysis and chi-square tests were performed. For interval and ratio-scaled data (e.g., satisfaction and quality of services or length of stay and patient concerns), associations were tested for significance using correlation analysis. T-tests were used to test for significant differences on client satisfaction and perceptions of overall service quality between genders and between users of private and public hospitals. One-way analysis of variance was also used to test for differences in the ratings when more than two groups (e.g., income or education categories) were involved.

\section{Results}

Respondents were asked to indicate factors that influenced their selection of a particular hospital. Five major reasons influenced their choice. These were distributed as follows (Table 1): Doctors' referrals (28.7 percent), reputation of the hospital (23.7 percent), referral by family and friends (17.4 percent), closeness to home (14.9 percent), cost (7.4 percent), and other miscellaneous factors ( 7.9 percent). However, most respondents also indicated a combination of the above factors as their second and third reasons influencing hospital choice. In other words, there are some tradeoffs involved in hospital choice; in an emergency, for example, the nearest hospital or clinic was preferred over a reputable hospital or the one prescribed by a physician.

Table 1 Factors Influencing Choice of Hospitals

\begin{tabular}{lcc}
\hline Reason for Choice & Frequency & Percentage \\
\hline Doctor's Reference & 58 & 28.7 \\
Reputation/Specialization & 48 & 23.7 \\
Friends/Relatives Influence & 35 & 17.4 \\
Closeness to Home & 30 & 14.9 \\
Cost Considerations & 15 & 7.4 \\
Miscellaneous & 16 & 7.9 \\
\hline Note: For any patient, a combination of the six factors generally influences \\
hospital choice.
\end{tabular}

Not surprisingly, doctors have a large say in patients' choice of hospitals. The influence doctors have over patients has policy implications because of its potential misuse. For example, if doctors are affiliated with specific hospitals and many are - they can direct patients to these hospitals, where quality of care may be sacrificed for the doctors' private gains. Such acts are not unusual, as reflected in the in-depth interviews. Similar behaviors have been reported in the case of laboratory and diagnostic tests: doctors refer patients to specific laboratories that provide kickbacks to the tune of 30-40 percent of diagnostic charges (Khan 1996). These behaviors are reflected in the questionable reputation that physicians have earned: in a recent public opinion poll (Holiday 1997:3), doctors earned ratings of only 5.47 on fairness, 4.62 on honesty, and 5.28 on trustworthiness, on a scale of $1-10$ (where 1 is low and 10 is high). Future studies should investigate whether patients who depend on their doctor are given appropriate advice or referrals. This is not to imply that such referrals are always aimed at exploiting the patients through a doctor-hospital alliance.

Reputation also influences people's choice of a hospital. A hospital that has a solid reputation clearly provides the expected services and meets the needs of patients; one with a poor reputation suffers low patient registration, underutilization of capacity, and increased overhead cost per client served. Thus, clinics and hospitals, both public and private, must invest in building their reputation. 
Referrals by friends and family also have a large influence on hospital selection. Those hospitals that seek to build a larger client base must provide customer satisfaction through credible and competent services which will eventually be communicated to friends and family members of satisfied clients. Many hospitals in the country have the opportunity to build their clientele base and enjoy longterm growth if they concentrate on providing quality services rather than short-term profits by taking advantage of clients. However, whether they will build a solid future grounded in an impeccable reputation or establish a questionable one by preying on hapless patients will also depend to some extent on the incentive structure - both rewards and punishments - designed to influence their behaviors.

Nearness to home influenced about 15 percent of the respondents. The strategic location of private hospitals may have played a large role in shaping their ability to carve out a large market share. Since access is an important factor in patients' selection of hospitals, this issue must be carefully considered by hospitals in their competitive stance and in the placement of new hospitals. It is, however, important to consider specific market segments (e.g., low income vs. high income groups) and their needs. Services and facilities should be built around these needs.

Cost is also an important consideration among clients; cost containment has received considerable attention in numerous studies (Griffin and Shaw 1995; Jiminez 1987). In fact, studies have shown that rural households spend little or not at all on health care, simply because spending more would mean reallocating their limited resources from other critical means of subsistence (Bangladesh Bureau of Statistics 1987). The average income in an urban household adjusted for cost of living, may also leave little to spend on preventive or curative health care. Stanton and Clemens (1989) suggest that introducing user fees to recover costs in the government system may restrict access of the most needy to medical care. Yet, with the rising demand for hospital services in Bangladesh and the need to recover increasing costs - especially in the public hospitals - price increases may have to be considered, with special arrangements for the destitute. Government subsidies may work for a while, but they cannot be the only solution to cost escalation. Allowing free market forces to determine prices, or allowing some combination of subsidies and market prices, may represent alternate solutions for different clientele groups. The use of government subsidies alone has not been very successful, as past experience suggests.

Respondents were also asked to indicate the reasons for selecting a particular hospital. The results indicated that 86 percent of the respondents went to a hospital to treat a problem; few went for routine checkups. In other words, few clients use hospitals for preventive or health "maintenance" services; most go for "repairs". This finding is not surprising, given the structure and organization of health care delivery in the country and the demands placed on the limited resources that are committed to this sector. However, it suggests that the concept of health maintenance and, hence, a better quality of life deserves greater attention in the country. If the quality of life of the population is to be enhanced, a system must be in place to provide greater health maintenance services and to build greater awareness of such services among the general population.

Table 2 Reasons for Visiting a Hospital

\begin{tabular}{lrr}
\hline Reason & Frequency & Percentage \\
\hline Checkup & 8 & 3.9 \\
Treat a health problem & 177 & 86.0 \\
Other & 22 & 10.1 \\
\hline
\end{tabular}

From the sample of respondents surveyed, it was also found that 48.3 percent went to a public hospital and 51.7 percent to a private hospital for their last hospitalization. In a span of about fifteen years, private clinics and hospitals have evidently carved out a large share of the market in Dhaka city. This could be attributed to a variety of factors such as capacity limitations in the public hospitals, growing population pressures, migration from rural to urban centers, poor services in the public hospitals, referrals of doctors affiliated with private hospitals, strategic location, and the perceived quality of attention and humane treatment provided by private hospitals.

Additional analyses using cross tabulations and chi-square tests were conducted to assess the association between demographic variables and choice of public or private hospitals. Research has shown that urban females have less access to health care compared to their male counterparts, 
and that this disparity increases with decreasing family wealth (Stanton and Clemens 1989: 1199-1205). However, studies on gender preferences regarding private or public care was not readily available. Table 3 indicates that a relationship between gender and type of hospital selected was weakly supported $\left(\chi^{2}=3.07, \mathrm{p}<.1\right)$. There was a slight tendency among female patients to select private hospitals while male patients were more inclined to select public hospitals. The likely cause for this association, deduced from the qualitative interviews, is that men are more inclined to go to the public hospitals because of cost considerations while women have greater privacy concerns and seek more specialized and personalized hospital care. This does not imply, however, that men do not have privacy concerns and are not interested in specialized and personalized care; rather the data reflect a general tendency regarding gender preferences. By controlling for other variables (e.g., income or age), gender preferences should be further investigated in future studies. The relatively small sample of this study did not allow for such in-depth investigation.

Table 3 Association Between Gender and Hospital Type

\begin{tabular}{lrrr}
\hline & \multicolumn{3}{c}{ Gender } \\
\cline { 2 - 4 } Hospital & Male & Female & Total \\
\hline Public & 64 & 33 & 97 \\
Private & 56 & 48 & 104 \\
Total & 120 & 81 & 201 \\
\hline
\end{tabular}

$\chi^{2}=3.07 ; p<.1 ;$ Cramer's $V=.12$.

A similar test between education level and type of hospital selected showed a statistically significant and stronger association (Cramer's $\mathrm{V}$ in Table 4) between the two variables $\left(\chi^{2}=8.98, p<.05\right)$. These results suggest that better educated people are more likely to seek private hospital care, while those with lower education levels are more likely to seek public hospital care. Since the better educated are likely to be more knowledgeable about health care practices in the country, their inclination to select private care over public care seems to reflect The World Bank's contention that the quality of public health care leaves much to be desired. Moreover, the better educated are also likely to demand better services. There is evidence of this behavior in Western countries, where the better educated buyers of health care are more aware and are able to evaluate all their options, and demand exactly what they need. Hospitals in Bangladesh that aspire to serve the better-educated may encounter similar demands, as this group is likely to become more vocal and demanding in future when it becomes more aware of better treatment alternatives and desire even better quality of care.

Table 4 Association Between Education and Hospital Type

\begin{tabular}{lrrrrr}
\hline & \multicolumn{5}{c}{ Education } \\
Hospital & $\mathbf{1}$ & $\mathbf{2}$ & $\mathbf{3}$ & $\mathbf{4}$ & Total \\
\hline Public & 21 & 29 & 40 & 7 & 97 \\
Private & 8 & 37 & 54 & 5 & 104 \\
Total & 29 & 66 & 94 & 12 & 201 \\
\hline
\end{tabular}

$\chi^{2}=8.98 ; p<.05 ;$ Cramer's $V=.21$.

$1=$ primary or less

$2=S S C$ and HSC

$3=$ graduate and post graduate

$4=$ otber

Association between income level and type of hospital selected resulted in a statistically significant and strong association (Cramer's $V$ values in Table 5) between the two variables $\left(\chi^{2}=19.12, \mathrm{p}<.001\right)$. This result reflects that those who can exercise their options because of their affluence are more likely to seek the services of private hospitals/ clinics. One reason for this may be the greater personal attention provided by these facilities. Both private and public hospitals must be cognizant of these findings to provide the needed services, especially if they are to attract the better educated or more affluent who might otherwise seek health care services in other countries.

Table 5 Association Between Income and Hospital Type

\begin{tabular}{lccccc}
\hline & \multicolumn{5}{c}{ Income } \\
Hospital & $\mathbf{1}$ & $\mathbf{2}$ & $\mathbf{3}$ & $\mathbf{4}$ & Total \\
\hline Public & 32 & 44 & 5 & 16 & 97 \\
Private & 15 & 41 & 22 & 26 & 104 \\
Total & 47 & 85 & 27 & $\mathbf{4 2}$ & 201 \\
\hline
\end{tabular}

$\chi^{2}=19.12 ; p<.001 ;$ Cramer's $V=.31$.

$1=<T k .5,000$

$2=T k .5,001-20,000$

$3=T k \cdot 20,001-40,000$

$4=T k .40,001$ and bigher 
The study also examined the length of a hospital stay which can be expensive. These expenses have grown over the years. Khan (1996) attributes these increases from 1982 to 1996 to inflation, illegal payments, and poor quality of services, among other factors. The actual cost of in-patient care was not sought in this study. Instead, the average length of time that patients spent in a hospital was assessed. While variations are expected depending on the nature of the health problem being treated, this study attempted to assess the average length of a hospital stay without controlling for case mix. The results indicated an average stay of 9.9 days. The variation was skewed by several long stays (maximum of 70 days). The modal value was 31 days. No comparable statistics were available to determine whether these figures overstated or understated the findings from previous research.

Additional analysis using t-tests indicated that there was no statistical difference in the length of stay between public and private hospitals $\overline{\mathrm{x}}_{\text {pub }}=10.66 ;\left(\overline{\mathrm{x}}_{\mathrm{prt}}=9.32, \mathrm{t}=.90\right.$, $\mathrm{p}>.30)]$. Neither was any statistical difference found between the length of stay in a ward as opposed to a cabin $\left(\bar{x}_{\text {cab }}=\right.$ $9.49, \bar{x}_{\text {wrd }}=10.29, t=-.58, p>.5$ ). Future research should endeavor to establish benchmarks regarding the cost and length of stay between wards and cabins or private and public hospitals for specific health complications. Such comparative information, when effectively communicated, should equip patients with better understanding and clearer expectations about the cost and average length of stay in a hospital for a particular ailment.

Length of stay was also correlated with several key patient concerns. The results shown in Table 6 indicate that longer stays are associated positively and significantly with nonavailability of needed medicines, poor upkeep of facilities, need to provide "tips" (i.e., gratuities) for services, lack of prompt services, a suffocating environment, and unexplained hospital costs.

Table 6 Correlates of Length of Stay

\begin{tabular}{llr}
\hline Scale Items & $\mathbf{r}$ \\
\hline 1. Necessary medicines were available at the hospital & $-.20^{*}$ \\
2. The facilities were clean & $-.17^{*}$ \\
3. Services were not provided without tips & $.22^{* *}$ \\
4. Services provided were prompt & $-.18^{*}$ \\
5. The hospital environment was suffocating & $.18^{*}$ \\
6. My health condition required complicated treatment & $.36^{* *}$ \\
\hline correlation coefficient $\quad * \quad=p<.01$ & \\
$* \quad=p<.05 \quad * \quad$ &
\end{tabular}

Respondents were further asked to indicate their overall satisfaction with the treatment they received while hospitalized. On a scale of 1-7, where 1 indicated "very dissatisfied" and 7 "very satisfied," the overall average score was 4.85 with a standard deviation of 1.56 . This score may seem to be somewhat high, but it has been shown in other contexts that self-reports of customer satisfaction are negatively skewed and exhibit a positivity bias (Peterson and Wilson 1992: 61-71), suggesting that the true score is lower. The obtained score above the mid-point value of the scale suggests only a slightly favorable satisfaction rating of overall hospital services.

When the scores for public and private hospitals were compared using a t-test, private hospitals earned significantly higher average ratings $\left(\overline{\mathrm{x}}_{\mathrm{pvt}}=5.21 ; \overline{\mathrm{x}}_{\text {pub }}=4.51, \mathrm{t}=\right.$ 3.33; $\mathrm{p}<.001$ ) compared to public hospitals. Similar findings have been reported in other countries (Van der Gaag 1995). Given the head start that public hospitals have had in Bangladesh, it is disconcerting that they earned a significantly lower rating on customer satisfaction than private hospitals. This may be explained by the incentive structures in the two types of hospitals. Because private hospitals depend on income from a client who holds the purse strings and, hence, controls their future earnings (either through revisits or by recommending them to other potential users of hospital facilities), private hospitals are likely to address client needs more effectively and efficiently. In public hospitals, on the other hand, there is no incentive or reward for initiative or extra effort of the staff to deliver customer satisfaction; nor is there any disincentive or punishment for providing poor quality of service, since the taxpayer will pay their salary regardless of how they treat patients. The incentive structure may explain the difference in services provided and the consequent satisfaction level of clients at private and public hospitals. Moreover, many doctors affiliated with public hospitals are also either affiliated with private hospitals or directly own private facilities. These doctors are likely to devote more of their limited time and effort to the private sector, where extra effort is rewarded.

Additional analysis shows no significant difference in patient satisfaction ratings between males and females. One-way ANOVA (analysis of variance) was used to test for statistical differences in satisfaction ratings between the different educational and income groups. No differences were found 
(For education groups, F3, $201=.548 ; \mathrm{p}>.6$ and for income groups, F3, $201=1.60 ; \mathrm{p}>.15$ ).

To validate the findings on overall satisfaction ratings, respondents were asked to rate, on a scale of 1-7, the overall quality of services received; 1 indicated "very poor" while 7 indicated "excellent" services. These scores were very strongly correlated with the satisfaction ratings $(r=.82$, $\mathrm{p}<.001$ ). Moreover, the average rating on overall service quality was 4.74 , with a standard deviation of 1.47 . When the scores for public and private hospitals were compared using a t-test, the private hospitals earned significantly higher scores $\left(\overline{\mathrm{x}}_{\mathrm{pvt}}=5.12 ; \overline{\mathrm{x}}_{\text {pub }}=4.36, \mathrm{t}=3.84 ; \mathrm{p}<.001\right)$, which is consistent with the satisfaction ratings.

Additional analyses showed no significant difference in the overall service quality ratings between males and females $\left(\overline{\mathrm{x}}_{\mathrm{m}}=4.65, \overline{\mathrm{x}}_{\mathrm{f}}=4.87, \mathrm{t}=-1.03 ; \mathrm{p}>.3\right)$. One-way ANOVA was used to test for differences in overall service quality ratings between the different educational and income groups. While no statistical differences were found between the educational groups (F3, $201=.401, \mathrm{p}>.75)$, a main effect was found for the income groups, indicating that at least one group mean was statistically different (F3, $201=$ 2.78; $\mathrm{p}<.05$ ). An examination of the means indicated that the highest income group gave the highest service quality rating (5.26) compared to the other income groups (means of 4.81, 4.49, and 4.74). One explanation for this finding is that the affluent group was able to afford private care (Table 5); better services may have resulted in the higher overall quality rating from this group.

\section{Conclusions}

The demographic trends suggest that as private hospitals have proliferated in Dhaka city, better educated and more affluent people have gravitated to these hospitals for health care. These people are likely to have better information about the quality of services provided by city hospitals and their inclination to select private care suggests, implicitly, that the quality of care is better at these facilities.

A class issue also seems to be surfacing in the realm of hospital care; people with limited resources would seem to be deprived of private care and the services available to the more affluent and better educated. While the ability to pay more should, realistically, enable the purchaser to get better services, what is important is that defined standards of service and treatment procedures must be established and ensured for all hospital patients. This minimum standard would have to be delivered and documented regardless of a patient's financial or educational status. The extra amenities, including creature comforts, are perhaps areas where additional charges could be levied depending on the client's ability to pay. Thus, whatever treatment procedures are involved, the minimum established guidelines must be available to all. While a class issue cannot be completely avoided, class should not find its way into standard procedures.

The determination and establishment of minimum standards should be entrusted to the profession itself, even though the present level of public confidence in health care professionals is decidedly low. External monitoring by the government or public watchdog groups may be employed only to ensure adherence to the standards. However, we stress that enforcement is best achieved through selfregulation. It is only when the profession is determined to regain its pride and prestige that appropriate standards can be installed and enforced. Some nudging may be required along the way by continuously gauging the public's sentiments regarding the quality of care they are receiving and conveying this to the profession through public forums.

The incentive structure must also play a role in ensuring that quality care is delivered. One solution is to tie part of the compensation of health care personnel in public hospitals to services rendered and feedback received from patients. This, of course, is a complex issue and has implications for pay scale administration, since health care staff, as government servants, are paid according to certain pay structures. While beyond the scope of this paper, this author feels that compensation flexibility is necessary to reward those who are dedicated to providing quality services. If compensation adjustments cannot be incorporated, benefits - including promotion, transfers, study leaves, and the like - could be tied to performance evaluation mechanisms. It would also be important to delimit or completely bar public sector practitioners from involvement with the private sector. If public health care personnel pledge their allegiance to the incentives of the private sector, they should not be cushioned by the taxpayer. 
The important factors that influence hospital choice suggest several policy implications. Since patients' choice of hospitals is influenced by doctors who, in general, have not earned the confidence of the general population, it is not inconceivable that a certain number of doctors would be misusing their power to exploit patients. The government can play a significant role in protecting patients; for example, every hospital could be required by law to offer only a government or professionally certified list of services. This list would be available to patients on demand. This information could also be made widely available to the public through mandated hospital information centers, bulletins, brochures, media campaigns, and related mechanisms. It would also be important to periodically evaluate and re-certify hospitals. A rating scale, something akin to those applied to financial institutions, could also be established to rate the quality of services based on hospital facilities, past performance records, and patient evaluations. The rating factors and mechanisms would have to be developed on the basis of inputs from patients and the profession. It would also be important to determine, specify, and strongly enforce the legal consequences for tampering with patient records and their evaluations.

The above process would lead to qualifying and ranking each and every hospital in its designated category. As the number of hospitals and clinics continues to grow, it is important to develop a national capability to periodically evaluate and publicly disseminate the ratings or rankings of all hospitals so that each service provider's reputation is widely known. Armed with this information, patients can make more informed choices. An aware public can also make the health care sector conform to established quality standards when they are disregarded. Not only will such dissemination of information be vital to the general public; it will also serve as an impetus for the lower-ranked hospitals to upgrade their services. If this mechanism of evaluation and dissemination can be firmly established, the overall quality of hospital services in the country should improve rapidly.

In addition, as an important determinant of hospital choice, hospitals must invest in building their reputation; this should also help take the pressure off established hospitals, which are often overburdened. Importantly, reputation enhancement can also slow the outflow of patients - and the country's hard-earned foreign exchange - to other hospitals in the region especially India, Thailand, and Singapore, and possibly even reverse these flows. Health care represents a critical service, and its demand should be growing globally; Bangladesh could eventually strive to become a regional provider of excellent health care services based on reputation. And, with an impeccable reputation in the region, foreign customers, in addition to domestic clients, could be targeted to boost the country's foreign exchange reserves. Of course, building a center of excellence requires a solid commitment from health care providers. That collective mind-set may take some time to build.

Hospital costs that include direct, indirect, and sometimes under-the-table payments have also increased to the point where many feel that going abroad for the same treatment involves comparable or even lower costs and better treatment. Clearly, cost containment strategies deserve immediate attention, especially to stem the outflow of foreign exchange. While it is easy to propose various types of interventions whereby the pricing of hospital services is made to conform to the socioeconomic conditions in the country (especially patients' ability to pay), such measures are likely to exacerbate customer service problems and enable the corrupt and exploitative practices engendered by scarcity and controls to continue. Instead, it is important for the Government to match supply and demand by building additional capacity or by encouraging the private sector to further expand services. If necessary, foreign capital and expertise may be invited so that new technology and modern managerial practices, with their attendant efficiencies, are introduced for local hospitals to emulate. If any intervention is contemplated, the first step should be to curb the sorts of corruption and malpractice reported in the media through vigilance, continuous monitoring, and rapid enforcement. Whether the Government can deliver on this basic requirement remains to be seen.

It may also be noted that the main reason why people visit hospitals is for restorative purposes; preventive care does not account for a significant proportion of hospital visits. Since preventive care can greatly enhance quality of life, it is important for policy-makers to consider developing avenues for this type of care. One way of achieving this is by encouraging private initiative to build health maintenance facilities to focus on preventive care only. Establishing 
information centers and low-cost health maintenance facilities, and training a cadre of paramedic staff who can perform basic checkups, can go a long way to nurture the concept of health maintenance in the country.

The average length of hospital stay was found to be 9.9 days with a modal value of 31 days. No comparative studies were found to determine whether the figures were in the acceptable range. A pertinent policy question is whether the average length of hospital stay is in the acceptable range, or patients are being made to stay longer than necessary due to inefficiencies or to run up their bills. Clearly, some benchmarks are necessary on this issue so that patients have some sense of what to expect in terms of hospital stay for specific ailments. When made aware, patients could raise questions when significant deviations occur from the norm. Based on hospital records, variations could also be monitored randomly by law enforcement agencies to assess whether patients are being treated fairly and efficiently.

The results also indicated significant associations between length of stay in a hospital and patient concerns. These associations are shown in Table 6. It is important to further investigate why patients requiring a longer stay feel that they have less access to needed medicines; this finding does not conform to the norms of proper service. Hospitals should not admit patients unless they are able to provide the full range of services and medical amenities needed for the healing process, especially since non-availability of medicines is likely to prolong the patients' suffering, as well as their hospital stay. The results also indicated that those needing a longer stay found the facilities less clean. It may be stressed that the upkeep of the facilities, regardless of a patient's length of stay, must conform to minimum standards if hospitals are to contain the spread of disease and hasten the recovery process. Unfortunately, in the absence of adequate monitoring and because of corrupt practices in the system, even these basic services are routinely neglected, adding to the sufferings of patients. In fact, a system of gratuities has evolved in the hospital environment to which patients must conform. This practice is widespread in the hospital environment; those who do not conform pay a price in other ways. It is imperative that these practices are rooted out, necessitating, perhaps, the introduction of innovative alternatives that rely on help from independent agencies and private groups.
Finally, the data suggest that private hospitals are delivering better services in terms of overall quality and customer satisfaction. This certainly raises the status of private hospitals which, apparently, are playing an important role in the health care system in Bangladesh. However, while it is easy to envisage a greater role for private facilities to meet the health care needs of the population, they must not be allowed unbridled expansion. In fact, if the private sector works side by side with the public sector, it is quite likely that it will raise the quality of both types of providers. Indirectly, it would mean that the average citizen will begin to experience better health services.

Appropriate levels of external monitoring, combined with self-regulation by the industry, should ameliorate the crisislike conditions in the health care sector today. From a policy perspective, harnessing the services of health care providers must be based on broad appeal, consensus among the providers, and the needs of the community. Policy prescriptions must also engender a genuine desire among the professionals to serve the public. That requires incorporating appropriate incentives. In addition, the profession itself must rise to the occasion with courage and determination to uproot inefficiency, mismanagement, and plain bad faith. Only then can the pride and prestige of health care professionals be re-established and public confidence in the health care delivery system restored.

\section{Acknowledgments}

The author acknowledges the encouragement and support of Dr A Majeed Khan, President, Independent University, Bangladesh (IUB). In addition, the assistance provided by Nuzhat Zaman, Sohel Shams, and Imtiaz Karim during data collection and data entry is appreciated. The contributions of other individuals associated with IUB are also acknowledged.

\section{References}

Bangladesh Bureau of Statistics. 1987. Report of Child Nutrition Status Module: Bangladesh Housebold Expenditure Survey, 1985-86, January.

Griffin, C and P Shaw. 1995. Financing Health Care in Sub-Sabaran Africa through User Fees and Insurance: Directions in Development Series. Washington DC: The World Bank.

"Low ratings for professionals". Dhaka. Weekly Holiday. January 17, 1997: 3 .

Jiminez, E. 1987. Pricing Policy in the Social Sectors: Cost Recovery for Education and Health in Developing Countries. Baltimore, MD; John Hopkins Press.

Khan, M Mahmud. 1996. Development of Private Healthcare Facilities in Dhaka City: Impacts on Cost, Access, and Quality. Seminar Paper, 
Center for Development Research, Dhaka, Bangladesh.

Peterson, RA and WR Wilson. 1992. Measuring customer satisfaction: fact and artifact. Journal of the Academy of Marketing Science 20 (1): 61-71.

Stanton, B and J Clemens. 1989. User fees for health care in developing countries: a case study of Bangladesh. Social Science Medicine 29 (10): 1199-1205.
The World Bank. 1987. Bangladesh: Promoting Higher Growth and Development. A World Bank Country Study. Washington DC: The World Bank.

Van der Gaag, J. 1995. Private and Public Initiatives: Working Together for Health and Education. Washington DC: The World Bank. 